\title{
Work-Family Conflict and Turnover Intentions: Moderated Mediation Model
}

\author{
Aleena Syed \\ Institute of Business Administration, Punjab University, Lahore, Pakistan \\ E-mail: Leenashah181@yahoo.com \\ Muhammad Bilal Ahmad (Corresponding author) \\ Hailey College of Commerce, Punjab University, Lahore, Pakistan \\ E-mail: bilalaahmad220@gmail.com \\ Hafiz Fawad Ali \\ Institute of Business Administration, Punjab University, Lahore, Pakistan \\ E-mail: fawadlai94@hotmail.com
}

\author{
Mian Muhammad Arif \\ University of Education, Lahore, Pakistan \\ E-mail: Dr.mianarif1965@gmail.com
}

Amna Gohar

E-mail: Goharamna3@gmail.com

Received: October 14, 2018 Accepted: November 15, 2018 Published: November 18, 2018 doi: $10.5296 /$ hrr.v2i1.13925

URL: https://doi.org/10.5296/hrr.v2i1.13925 


\begin{abstract}
In this research, the relationship between work-family conflicts of female doctors with turnover intentions is examined along with the moderating role of perceived organizational support and taking job stress as a mediator. A self-administered questionnaire was used to collect data from 270 female doctors who were practicing in different tertiary care hospitals of Lahore. For analyzing the data, the researcher used IBM SPSS and PLS-SEM. Results of the study confirmed that a positive relationship exists between WFC and intention to quit jobs in female doctors. Results also revealed that POS acts as a moderator between WFC and quit intentions but rejected the hypothesis of stress as a mediator between work-family conflict and intentions to leave the profession in the case of female doctors of Lahore. The past studies on work-family conflict were mostly conducted on the scenario of western countries particularly in America but the present study gives an insight of the relationship between work-family conflict and turnover intention of female doctors in Pakistan.
\end{abstract}

Keywords: Work-family conflict, Female doctors, Perceived organizational support, Turnover intentions, PLS-SEM

\title{
1. Introduction
}

Female's participation in the workforce has increased rapidly in Pakistan. The overall unemployment rate of females has sharply declined from 16.5 to 9 percent in past few years against (Mirza, 2015). There are different roles allocated for men and women in Pakistan's society. So women who work outside their house have to bear extra responsibility (Gallup, 2009). Basically the society of Pakistan is male-dominated. Female are discriminated against due to gender and due to their social status, (Tazeen, et al., 2011). There are a lot of challenges that a woman in Pakistan face if they want to work outside the four walls of their house. They have to perform their home responsibilities as well (Ruqia, Ghulam, Muhammad, $\&$ Fouzia, 2015). Because of their dual roles, they are the most affected population of work-family conflict in this society. In the past, very little work is done to discover the relationships between work-family conflict, turnover intentions, stress and perceived organizational support of females in Pakistan. The current study focuses on working female doctors, to explore the relationship of these variables in female doctors. The only the female population is selected because, in Pakistan, female faces work-family conflict more.

\section{Work-Family Conflict}

The famous researchers of work-family conflict Greenhouse and Butell gave following the definition of it "a form of inter-role conflict in which the role pressures from the work and family domains are mutually incompatible in some respect. That is participation in the work (family) role is made more difficult by virtue of participation in the family (work) role" (Fabienne, Ursula, Achim, \& Norbert, 2011) .

It is a smaller area of study of work-life conflict and occurs when activities of family and work clash with each other. It can be in both directions either WIF or FIW in the domain of work and family (Frone, Yardley, \& Markel, 1997). Most people experience work to life conflict more because of non-flexibility of work schedules (Greenhaus \& Parasuraman, 1999). 


\section{Macrothink}

Literature provides evidence that long working hours also causes WFC having serious consequences on the health of the employees (Philip, Michael, David, \& Ann, 2004).

The major portion of the available literature on WFC studies is in the context of European countries. The socio-cultural context of the majority of the countries where research on work and family conflict is conducted is nearly simila (Spector P. A., 2009). Developing countries face negligence in this aspect. (Joplin, Shaffer, Francesco, \& Lau, 2009) Due to cultural and societal differences, the studies of the western countries cannot be generalized in the developing and Muslim countries (Spector, Allen, Poelmans, \& Cooper, 2009). Nowadays, researchers have started to address developing countries in order to fill this gap (Wharton \& Blair-Loy, 2006)

\section{Job Stress}

Stress is considered an important issue since the evolution of humans. The factors that cause stress are still needed to find despite the fact that a lot of studies have been conducted on it already. The literature says that the human body responds to stress in three ways as she explained. In 1986, a lot of studies were conducted on job stress and it was empirically found that "it has a long list of psychological and physical adverse effects on the human body". It also lessens the individual's earning potential.

Job stress when becomes severe causes insomnia that leads many complicated medical conditions. It also makes an individual addicted to drugs and alcohol. In professional life, it is a major cause of "interpersonal conflicts". Physically and mentally sick employees adversely affect organizational overall productivity. I.e. low productivity, increased sick leaves and increased the loss of human capital. (Saleem, Ahmed, \& Saleem, 2016)

Many factors that lead the organization towards inefficiency and failure are stress drove i.e absenteeism on medical reasons, high turnover and lower satisfaction towards the job, poor quality, and higher medicinal expenses (Wheeler \& Riding, 1994). There are different types of stress having differing intensities that depend upon the type of profession. Studies are also conducted to find the relationship between job stress and employee performance. Researchers have found empirical evidence on the negative relationship between the two said variables. Some studies also gave results that moderate stress increases the performance of employees. (AbuAlRub, 2004)

In the recent past, a lot of researches have been conducted on occupational stress and many books have also been written on it due to which people are now aware of it and they try to control it. But very little work is conducted on job stress by taking organizations into consideration and this area of study is still under-researched. The results of the studies give evidence that job stress is a major factor that contributes to health-related issues of employees and organizational problems such as high turnover, employee dissatisfaction and low productivity and commitment. A large budget is spent on these problems every year by organizations. The need of the hour is "to conduct more studies on stress management in work organizations" so that solutions to these problems can be identified. There is a negative to a negative correlation between stress and job performance (Chaudhry, Malik, \& Ahmad, 2011) 


\section{Perceived Organizational Support}

Perceived Organizational Support (POS) is defined as "employees' perception concerning the extent to which the organization values their contribution and cares about their well-being". Socio-emotional needs of employees are fulfilled by POS and it also increases the effective commitment of employees (Kim, Eisenberger, \& Baik, 2016)

Studies give evidence that there is a strong relationship between POS and affective commitment. Meyer et al. (1990) the studies also give evidence of positive "positive relationship of perceived organizational support and change in effective organizational commitment". Studies also say that felt the obligation of employees can act as a mediator between the relationship of POS and affective commitment (Kim, Eisenberger, \& Baik, 2016). The literature suggests a positive relationship between supervisor and POS. The negative treatment of supervisors on POS is still not studied sufficiently

\section{Turnover Intention}

"Turnover intention can be defined as the wish of an employee to leave the workplace". It is the planning of an employee to leave the job for other job or due to any reason. When an employee leaves a job and another person is inducted in his place, TI happens. Many types of research have already been conducted on this.

A study conducted by Riley in 2006 found that there is a positive correlation between TI and WFC. The results also show that there is a direct positive relationship between the two variables. Increased rate of turnover also causes increased recruitment and training expenses of organizations the factors that cause turnover are numerous. According to the available literature the most highlighted of them are high workload, low job involvement, less job satisfaction, and increased stress. Scholars who have conducted research on this topic consider turnover a very important issue to be addressed in all the organizations and endorse the execution of "family-friendly policies" that balances work and family lives of employees. Literature suggests that the work-life balance policies significantly reduces the job stress and turnover intentions of workers.

Cohen In 1997 found in his study that due to work overload and accumulated stress, WFC arises and employees become highly frustrated due to which employees intend to leave the job (Greenhaus \& Beutell, 1985).

\section{Proposed Hypotheses}

H1: Higher work-family conflict causes increased turnover intentions.

H2: A positive correlation exists between WFC and level of job stress

H3: Job stress and turnover intention have a direct positive relationship

H4: Job stress acts as a mediator between the relationship of WFC and TI

H5: POS acts as a moderator between the relationship of WFC and TI 
THEORETICAL FRAMEWORK

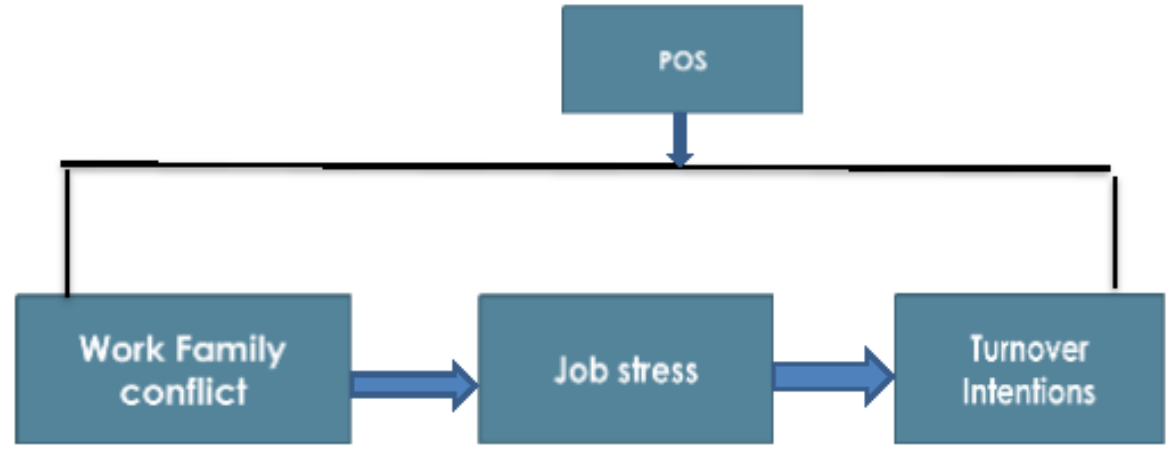

Figure 1. Theoretical model

\section{Methodology \& Results}

For collecting data from female doctors, a self-administered questionnaire was used. This technique is less expensive and provides complete data in relatively less time as compared to other methods. Consent forms were also got filled by the doctors who responded to the questionnaire and all the ethical standards of research were fulfilled. The respondents returned the filled questionnaires to the researcher. In this study Cross-sectional data were collected from female doctors of different age groups of six tertiary care hospitals of Lahore. The four variables that are used in the study are, perceived organizational support (POS), Work-family conflict (WFC), and turnover intention (TI) and job stress (JS). The hospitals were randomly selected from a list of public sector hospitals. All the doctors are full-time employees of these hospitals. Total 300 questionnaires were circulated out of which 270 were given back. Any authentic internet source or PMDC failed to provide total female doctors population working in Lahore, therefore, the researcher took the help of available literature and found a method to select the sample size of the unknown population. N:q rule was followed to select the sample size for this study which was proposed by Jackson in 2003. N represents the "number of parameters" and q is the "statistical estimate". Generally, 20:1 reflects an ideal sized. Kline mentions in his book that 200 is the ideal sample size for SEM to be implied. Hair et al. highlight 5:1 to be the minimum ratio for each variable. In the available literature where SEM is used, the researcher found 10:1 more acceptable relation that is used by many by many academics. Therefore in the current study, the sample size is selected by a 10:1 ratio. The questionnaire had 27 items to measure the four variables, therefore, sample size comes out to be 270 for this study.

For the measurement of variables, the researcher adopted scales developed by different authors. WFC was measured by using 10 item scale of Richard G. Netemeyer (1996) the sample items of scale are "Things I want to do at home do not get done because of the demands my job puts on me." And "My job produces a strain that makes it difficult to fulfill family duties". All the items had greater than 0.8 value of the coefficient of alpha. Job stress was measured by 4 items scale developed by Hewitt, Crank, Culbertson, and Regoli in 1995. The sample items include "A lot of time my job makes me very frustrated or angry" and "I 
am usually under a lot of pressure when I am at work". To measure TI the researcher used Calloway et al 4 item scale which was developed in 1999. The value of "coefficient of alpha" of this scale was 0.78 sample items are "I am thinking about leaving practice" and "I am planning to go abroad".

Researcher measured POS by using the eight-item scale made by Robert Wiesenberger. A sample item is: "My hospital/ HOD really cares about my well-being". In this study, the researcher used IBM SPSS and smart PLS -SEM to quantify the data. The research is purely descriptive and hypothesis testing is also done. The characteristics of all the variables, composition and individualities of the participants of the study are described through descriptive statistics. The assumptions that are made in the previous part are verified or rejected by hypothesis testing.

First of all the raw data that was collected from doctors was read by the researcher and all the invalid or incomplete questionnaires were discarded when the data was uploaded to IBM SPSS to run the regression tests.

Table 1. Descriptive statistics

\begin{tabular}{llllll}
\hline & $N$ & Minimum & Maximum & Mean & Standard deviation \\
\hline Turnover Intentions & 270 & 1.00 & 5.00 & 3.0000 & 1.0101 \\
Perceived organizational support & 270 & 1.00 & 5.00 & 2.8241 & 1.0956 \\
Job stress & 270 & 1.00 & 5.00 & 2.6593 & 0.8668 \\
Work family conflict & 270 & 1.00 & 5.00 & 2.2370 & 0.7934 \\
Valid (N) & 270 & 1.00 & 5.00 & & \\
\hline
\end{tabular}

From the above table of descriptive statistics, it is mentioned that the data was collected from 270 female doctors and they responded on a "5 point Likert scale" where maximum value was 5 and the minimum value was 1 .

Table 2. Frequency distribution of age

\begin{tabular}{lllll}
\hline Age groups & Frequency & Percent & Valid percent & Cumulative percent \\
\hline $23-27$ & 103 & 38.1 & 38.1 & 38.1 \\
$28-32$ & 108 & 40.0 & 40.0 & 78.1 \\
$33-37$ & 42 & 15.6 & 15.6 & 93.7 \\
$38 \&$ above & 17 & 6.3 & 6.3 & \\
Total & 270 & 100 & 100 & \\
\hline
\end{tabular}

From the table above it is evident that there were four age groups of doctors from where the data was collected $38 \%$ doctors were between the age of $23-2740 \%$ were $28-32,15 \%$ of 


\section{Macrothink}

Human Resource Research

ISSN 1948-5441 2018, Vol. 2, No. 1

doctors who participated in the research were between the age of 33-37 and only $6 \%$ of doctors who are above 38 responded therefore we can infer that mostly young and practice doctors participated in the study.

Table 3. Frequency distribution of marital status

\begin{tabular}{lllll}
\hline Marital status & Frequency & Percent & Valid percent & Cumulative percent \\
\hline Single & 92 & 34.1 & 34.1 & 34.1 \\
Married & 178 & 65.9 & 65.9 & 100 \\
Total & 270 & 100 & 100 & \\
\hline
\end{tabular}

The table above depicts the marital status of the doctors who participated in the study and shows that 34\% were single and 65\% were married. Tests were run in SPSS of the data and it was found that the data was normally distributed with no outliers and was homoscedastic. Then the data was uploaded in smart PLS SEM software. The researcher examined the indicator reliability, internal consistency reliability and discriminant and convergent validity of the model and found the measurement mode acceptable then the paths were assessed. In PLS SEM the researcher analyzed Measurement and structural model.

Table 4. Measurement model

\begin{tabular}{|c|c|c|c|c|c|c|}
\hline Latent Variable & indicators & Loadings & $I R$ & $C R$ & $A V E$ & $D V$ \\
\hline \multirow{11}{*}{$\begin{array}{l}\text { Work-Family } \\
\text { Conflict }\end{array}$} & WFC1 & 0.863 & 0.744 & \multirow[t]{11}{*}{0.9082} & \multirow[t]{11}{*}{0.5001} & \multirow[t]{11}{*}{ Yes } \\
\hline & WFC2 & 0.881 & 0.776 & & & \\
\hline & WFC3 & 0.887 & 0.786 & & & \\
\hline & WFC4 & 0.903 & 0.815 & & & \\
\hline & WFC5 & 0.900 & 0.810 & & & \\
\hline & FWC1 & 0.702 & 0.502 & & & \\
\hline & FWC2 & 0.897 & 0.804 & & & \\
\hline & FWC3 & 0.897 & 0.804 & & & \\
\hline & FWC4 & 0877 & 0760 & & & \\
\hline & FWC5 & $0.8 / 2$ & & & & \\
\hline & & 0.872 & 0.760 & & & \\
\hline \multirow[t]{4}{*}{ Job stress } & JS1 & 0.820 & 0.672 & \multirow[t]{4}{*}{0.9039} & \multirow[t]{4}{*}{0.7020} & \multirow[t]{4}{*}{ Yes } \\
\hline & JS2 & 0.890 & 0.792 & & & \\
\hline & JS3 & 0.795 & 0.632 & & & \\
\hline & JS4 & 0.844 & 0.712 & & & \\
\hline \multirow{3}{*}{$\begin{array}{l}\text { Perceived } \\
\text { Organizational } \\
\text { Support }\end{array}$} & POS1 & 0.787 & 0.619 & & & \\
\hline & POS2 & 0.717 & 0.514 & & & \\
\hline & POS3 & 0.756 & 0.571 & 0.8532 & 0.5572 & Yes \\
\hline
\end{tabular}




\begin{tabular}{llllllll}
\hline & POS4 & $0.70,0$ & 0.500 & & & \\
& POS5 & 0.767 & 0.588 & & & \\
& POS6 & 0.748 & 0.559 & & & \\
Turnover & POS8 & 0.782 & 0.611 & & & \\
Intentions & TI1 & 0.701 & 0.500 & 0.8526 & 0.5936 & Yes \\
& TI2 & 0.789 & 0.622 & & & \\
& TI3 & 0.702 & 0.502 & & & \\
& TI4 & 0.882 & 0.777 & & & \\
\hline
\end{tabular}

The indicator reliability in the above measurement model of the research shows the value of all the items is equal to or above 0.5 which is a threshold. The factor loadings of all the items are also mentioned in the table. It is evident that they are also above the threshold value of 0.7 . These values show that "the variance shared between the construct and its indicator is larger than the measurement error variance in this model" (Jos, Tomas, \& Christion). The value of factor loadings should be equal to 0.7 or above because the value of indicator reliability is obtained by taking a square of factor loading and the threshold value of indicator reliability is 0.5 .

In PLS SEM composite reliability is used to calculate the "internal consistency reliability" of the measurement model. The value of composite reliability varies from 0 to 1 and higher value indicate the higher reliability of variables. The measurement model table above indicates that for the data of this research its value for work-family conflict is 0.9082 , turnover intentions is 0.8526 , POS is 0.8532 and of the job, stress is 0.9039 . As these values are close to 1 and above the threshold of 0.6 and below the threshold of 0.95 , therefore we can infer that internal consistency reliability is high.

AVE values are examined to check the variance of the indicator the variance is checked through convergent validity. If the value of convergent validity is 0.50 or above, it shows that more than half of the variance of the indicators is explained by the variable which is being. It can be clearly seen in the above table that AVE values are above 0.5 . The Cronbach alpha was examined to check the internal consistency which shows that whether they produce the same results or not. Reliability is checked through Cronbach's Alpha. The minimum value of it is 0.7. It is shown in the table above that value of Cronbach's alpha is higher than 0.7 so we can say that the questionnaire that we used was reliable.

\subsection{Structural Model}

In the structural model, the major issue is Collinearity. This problem is seen when the value of the variance inflation factor (VIF) is higher than 5 (Hair et al., 2011). VIF report is not generated by SEM, therefore, the researcher used SPSS. The values of VIF was under the threshold level so there were no issue of multicollinearity.

In addition to multicollinearity, the $\mathrm{f}^{2}$ effect size is also studied in the structural model. It tells the effect of an exogenous variable on endogenous variable's $\mathrm{R}^{2}$ value. The overall contribution of the research study is indicated by effect size, therefore, it is very important. The researchers Marcelin, Chin, and Newsted (1996) say that the researcher should not only 
report the relationship's significance but also effect size. As the value of $\mathrm{R}^{2}$ of the latent variable for this study is 0.385 so it is inferred that it is satisfactory.

Table 5. PLS path Model estimation

\begin{tabular}{llll}
\hline Paths & Path Coefficient & T-Values & Significance levels \\
\hline WFC > TI & 0.346 & 5.927 & $* *$ \\
JS > TI & 0.060 & 0.997 & Not significant \\
POS > TI & 0.487 & 11.720 & $* *$ \\
WFC $>$ JS & 0.411 & 7.696 & $* *$ \\
\hline
\end{tabular}

The value of path coefficients and T- statistics by bootstrapping tells the extent of the relationship between variables. It can be seen in the table above that all the relationships except JS $>$ TI are significant. The non-significant relationship shall be explained later for checking the mediation relationship of job stress, $\mathrm{T}$ values were calculated using a two-step bootstrapping procedure. The general rule of thumb that is mentioned in hair et al ' $\mathrm{s}$ book is that if the value of VAF is equal or above 0.2 it indicates partial mediation and if its value is lower then there is no mediation. Since this value is 0.0663 for this study, which is lower than 0.2 it is clear that job stress is not a mediator between IV and DV for this study. For checking moderation relationship a moderating variable was attached between WFC and TI and bootstrapping was run through PLS-SEM. Its value came out to be 1.964 which is equal to a threshold value for moderation, therefore, we can say that POS acts as a moderator between IV and DV for this study.

\section{Discussion \& Conclusion}

The purpose behind conducting this study was to identify what relationship exists between the WFC and quit intentions in female doctors. The role of stress was also checked as a mediator and the role of perceived organizational support as a moderator between WFC and quit intention was checked separately for this study. Work-Family conflict is acting as an independent variable for current study and turnover intentions of female doctors as a dependent. Different statistical tools are used to check the relationships under study. The results are discussed as follows:

The first hypothesis for this study is supported by the results i.e. a positive relationship exists between WFC and TI of female doctors who are working in tertiary care public hospitals of Lahore. The path coefficient values for this relationship is 0.346 and $t$ value is 5.27 that supports the hypothesis. The available literature also supports these results. A researcher Alvin in 2013 conducted a research on Malaysian service sector employees. The study also revealed a significant positive relationship between work-family conflict and intentions to leave the job.

The second hypothesis of the study is also supported by the results that there exists a positive relationship between work-family conflict and job stress as the path coefficient value is 7.696 for the relationship and $\mathrm{t}$-values is 0.411 . Higher the level of conflict between work and 


\section{$\Lambda$ Macrothink}

family, higher will be the job stress. Same results that a positive correlation exists between WFC and job stress (Cropanzano, Rupp, \& Byrne, 2003). The third hypothesis is however rejected by the results obtained for the data of this study i.e Increased job stress leads to increased intentions to quit among female doctors. Although studies conducted in other countries under different cultures support this hypothesis that job stress acts as a mediator between WFC and TI but in the context of Pakistan, the results did not support this hypothesis and job stress failed to act as a mediator between WFC and TI. The VAF value for a said relationship is 0.0663 which is too low, it should be equal to or above 0.2 for a variable to act as a mediator. The values of $t$ statistics for this relationship is 0.9484 . The results show that job stress is not a mediator between the IV and DV of this study. There are multiple reasons behind this result that can be identified through more studies on this topic. The apparent reasons behind this are that the doctors do not get the desired jobs easily because there is a very tough competition and also the government does not provide good facilities for the doctors. The policies are not desirable and the service structure is not defined therefore one who gets job consider himself very lucky.

The fourth hypothesis i.e, job stress is acting as a mediator between WFC and TI is automatically rejected by the above-mentioned results. The moderation relation of perceived organizational support between WFC and TI is also confirmed by results by bootstrapping we got value 1.964 which is equal to the threshold from this result we can assume that if organizational support is given, quit intentions can be reduced. There are not adequate facilities for doctors even in public sector tertiary care hospitals. Therefore the ablest and competent doctors leave jobs or move abroad the family-friendly policies in hospitals can reduce this brain drain. Due to the conflict of work and family lives female doctors of Lahore choose their families and leave their profession. The social and cultural norms of Pakistan also expects from women to fulfill their family responsibilities first. Therefore many women who are professionally qualified do no work at all. This study also uncovers this fact that due to work-family conflict, female faces stress but they do not leave their jobs due to stress the reasons behind this fact is yet unidentified but it can be observed that jobs of the doctors are already stressful and they become so immune to fight with stress or one of the reasons behind this could be unemployment. As the jobs are not available easily in government sector due to central induction policy, therefore, one who gets the job does not leave it due to job stress.

\section{Limitation \& Future Directions}

The research was conducted in a limited time frame, therefore, a small segment of the population of female doctors was selected. Secondly, the data was collected only from one side the hospital administration was not considered for the data collection. The study is cross-sectional due to a shortage of time and resources and also fewer variables are considered for this study.

The research can be extended by adding many other variables that can cause problems for women at workplace and needed to be addressed in our society such as workplace harassment of females at workplace, gender-based discrimination at workplace and work-family enrichment. By taking data from hospital administration too will polish the quality of results. In the future, this research can also be conducted using qualitative research methodology that can unveil many hidden facts. The study can be conducted in a more diverse population of 
female doctors to find other facts behind their intentions to leave their jobs and also this study can be done by a qualitative approach. Some other variables can also be taken into consideration for example work-family enrichment

\section{References}

AbuAlRub, R. F. (2004). Job Stress, Job Performance, and Social Support Among Hospital Nurses. JOURNAL OF NURSING SCHOLARSHIP. https://doi.org/10.1111/j.1547-5069.20 04.04016.x

Allen, N., \& Meyer, J. P. (1990). The Measurement and Antecedents of Affective, Continuance and Normative Commitment to the organization. Journal of Organizational Psychology. https://doi.org/10.1111/j.2044-8325.1990.tb00506.x

Chaudhry, A. A., Malik, M. I., \& Ahmad, I. (2011). Examining the Relationship of Work-Life Conflict and Employee Performance (A Case from NADRA Pakistan). International Journal of Business and Management. https://doi.org/10.5539/ijbm.v6n10p170

Cropanzano, R., Rupp, D. E., \& Byrne, Z. S. (2003). The Relationship of Emotional Exhaustion to Job Performance Ratings and Organizational Citizenship Behavior. Journal of applied psychology. https://doi.org/10.1037/0021-9010.88.1.160

Fabienne, T. A., Ursula, F., Achim, E., \& Norbert, K. S. (2011). A Meta-Analysis of Work-Family Conflict and Various Outcomes With a Special Emphasis on Cross-Domain Versus Matching-Domain Relations. Journal of occupational health psychology.

Frone, M. R., Yardley, J. K., \& Markel, K. S. (1997). Developing and testing an integrative model of the work-family interface. Journal of vocational behavior. https://doi.org/10.100 6/jvbe.1996.1577

Gallup, G. (2009). Gallup Pakistan poll findings on gender roles.

Greenhaus, J. H., \& Beutell, N. J. (1985). Sources of conflict between work and family roles. Academy of management review. https://doi.org/10.2307/258214

Greenhaus, J., \& Parasuraman. (1999). Research on work, family, and gender: Current status and future directions. Handbook of gender and work.: Thousands of Oaks.

Hair, J. F., Ringle, C. M., \& Sarstedt, M. (2011). PLS-SEM: Indeed a Silver Bullet. Journal of Marketing Theory and Practice. https://doi.org/10.2753/MTP1069-6679190202

Joplin, J. R., Shaffer, M. A., Francesco, A. M., \& Lau, T. (2009). The Macro-Environment and Work-Family Conflict Development of a Cross-Cultural Comparative Framework. International journal of cross-cultural management.

Kim, K. Y., Eisenberger, R., \& Baik, K. (2016). Perceived organizational support and affective organizational commitment: Moderating influence of perceived organizational competence. Journal of Organizational Behavior. https://doi.org/10.1002/job.2081

Kelloway, E. K., \& Francis, L. D. (2011). Management of occupational health and safety. Toronto: Nelson Education.

Mirza, s. (n.d.). Pakistan gender news.

Netemeyer, R. G., Boles, J. S., \& McMurrian, R. (1996). Development and Validation of Work-Family Conflict and Family-Work Conflict Scales. Journal of Applied Psychology. 


\section{Macrothink}

Human Resource Research

ISSN 1948-5441

2018, Vol. 2, No. 1

Philip, B., Michael, Q., David, K., \& Ann, W. (2004). Working hours, work-life conflict and health in precarious and "permanent" employment.

Ruqia, S., Ghulam, S., Muhammad, Z. F., \& Fouzia, Y. (2015). Determinants of Female Employment Status in Pakistan: A Case of Sahiwal District. Pakistan journal of commerce and social sciences.

Saleem, I., Ahmed, R., \& Saleem, N. (2016). Mediating Role of Work Exhaustion: The Missing Linchpin to Address Employee's Turnover. Journal of Behavioral Science.

Spector, P. A. (2009). An international comparative study of work-family stress and occupational strain. Poelmans, S. A. Y.

Spector, P., Allen, T., Poelmans, S. A., \& Cooper, C. L. (2009). An international comparative study of work-family stress and occupational strain. In S. A. Y. Poelmans (Ed.) Work and family: An international research perspective. An international comparative study of work-family stress and occupational strain. In: Poe Lawrence Erlbaum Associates, Inc.

Sylvie, F. R., Blanchard, C., \& Robert, J. V. (2002). A Motivational Model of Work Turnover. Journal of Applied Social Psychology.

Tazeen, S. A., Gunilla, K., Raisa, G., Nargis, A., E.,., Ingrid, M. (2011). Gender roles and their influence on life prospects for women in urban Karachi, Pakistan: a qualitative study. Global health action.

Wharton, A. S., \& Blair-Loy, M. (2006). Long Work Hours and Family Life: A Cross-National Study of Employees' Concerns. Journal of Family Issues. https://doi.org/10.1177/0192513X05282985

Wheeler, H., \& Riding, R. (1994). Occupational stress in general nurses and midwives. International Journal of Nursing studies.

\section{Copyright Disclaimer}

Copyright for this article is retained by the author(s), with first publication rights granted to the journal.

This is an open-access article distributed under the terms and conditions of the Creative Commons Attribution license (http://creativecommons.org/licenses/by/3.0/). 